\title{
LA AUTORIDAD PEDAGÓGICA DESINVESTIDA Y LA RECONFIGURACIÓN DE SUS LEGITIMIDADES INSTITUYENTES ${ }^{1}$
}

\author{
Pablo Neut Aguayo ${ }^{2}$
}

\section{Resumen / Abstract}

El proceso de democratización social en curso ha implicado una progresiva revisión de las formas en que se ejerce la autoridad dentro del escenario educativo chileno. El siguiente trabajo representa un intento por abordar teórica y empíricamente las formas de configuración de la autoridad pedagógica actual, los elementos de continuidad y cambio verificados en su ejercicio y las nuevas legitimidades que permiten su emergencia. Para esto se realizó un estudio de caso basado en entrevistas en profundidad aplicadas a 20 estudiantes de dos instituciones educativas vulnerables ubicadas en Santiago.

Palabras clave: autoridad pedagógica, crisis de la autoridad, declive institucional, obediencia voluntaria, legitimidad.

THE PEDAGOGICAL AUTHORITY DISINVESTED AND THE RECONFIGURATION OF THEIR INSTITUTING LEGITIMACY

The process of social democratization process has involved an ongoing review of the ways in which authority within the Chilean educational scenario is exercised. The following paper represents an attempt to address theoretical and empirical ways of setting the current pedagogical authority, the elements of continuity and change verified in practice and the new legitimacy that allowed his emergency. For this, was performed a case study based on in-depth interviews

1 Este artículo se enmarca dentro del proyecto FONDECYT No 1110733: "La autoridad y la democratización del lazo social en Chile", dirigido por la Dra. Kathya Araujo.

2 Pontificia Universidad Católica de Chile. E-mail: paneut@uc.cl 
with 20 students from two vulnerable educational institutions located in Santiago.

Keyword: pedagogical authority, crisis of authority, institutional decline, willing obedience, legitimacy.

"Las demandas de igualdad se afirman en nuevos territorios y por otras vías. Más allá de su traducción en el derecho, en verdad, apoyándose en grandes principios políticos y jurídicos, la igualdad aspira a ser concretada en la vida social cotidiana, la de todos los días. La igualdad deja de ser el horizonte exclusivo de la inclusión política o de las movilizaciones sociales y se convierte en un anhelo interactivo" (Araujo y Martuccelli, 2012, vol I: 93)

\section{Introducción}

El análisis de la autoridad pedagógica opera como un crisol de los nudos y tensiones que emergen del proceso de democratización social en curso. En efecto, el aumento progresivo de las demandas por una mayor igualdad, particularmente en las instituciones de socialización primarias (escuela y familia), ha erosionado los pilares tradicionales en los que se sustentaba la autoridad, diluyendo el lazo social que proporcionaba legitimidad y estabilidad a una estructura social jerarquizada y vertical.

La desinvestidura de la autoridad, sin embargo, se ha materializado sin un aparente reacople o sustitución de sus fuentes instituyentes, originando un "vacío relacional". En particular, las autoridades escolares reclaman constantemente, la mayoría de las veces con una manifiesta perplejidad, sobre la "crisis de la autoridad", la anomia estudiantil y la imposibilidad de controlar a un grupo de sujetos indispuestos frente a su mandato. ¿Significa esto el fin de la autoridad, particularmente en el escenario educativo?

Esta es la pregunta de fondo que motiva el desar rollo del siguiente trabajo. Nuestro objetivo principal es comprender los modos en que se producen, 
legitiman y despliegan las relaciones de autoridad dentro del espacio escolar, focalizando nuestra indagación en el contexto de aquellas instituciones que reciben mayoritariamente a jóvenes "vulnerables". Para ello, realizamos un estudio de caso múltiple (Mucchielli, 1996: 104) basado en 20 entrevistas en profundidad, las que fueron aplicadas a estudiantes de educación media de dos liceos capitalinos. ${ }^{3}$

En términos expositivos, el texto se divide en tres grandes acápites que, siguiendo una lógica que transita desde lo general a lo particular, operan como un "embudo temático" destinado a analizar integralmente la problemática de las relaciones de autoridad en el escenario escolar. De esta manera, comenzaremos revisando las propuestas de los principales referentes teóricos que se han ocupado de indagar en dicha problemática dentro de las ciencias sociales. En un segundo momento, analizaremos el tratamiento que ha efectuado la sociología de la educación en torno a la misma. Finalmente, exponemos los resultados empíricos obtenidos en nuestro estudio de caso, articulando las conclusiones con el marco general revisado anteriormente.

\section{¿Qué es la autoridad?}

El debate en torno a la noción de autoridad se ha llevado a cabo bajo el telón histórico del siglo XX. Éste, a decir de Hobsbawm, se ha erigido como el periodo más violento y destructivo de la historia debido a la proliferación de las "guerras de religiones seculares" (Hobsbawm, 1998), es decir, la pugna entre proyectos político-ideológicos (liberalismo, marxismo y nazi-fascismo) que reclamaron una legitimidad total, sin concesiones de ningún tipo hacia sus rivales. En la práctica, dicha pugna fomentó el desarrollo de tecnologías aplicadas a la destrucción masiva, posibilitó el surgimiento de los regímenes totalitarios y se expresó encarnizadamente en las guerras mundiales. Todas ellas, experiencias que afectaron profundamente la conciencia de la humanidad. No es de extrañar, por tanto, que en este contexto general de expansión del "poder total" se impulsara el debate en torno a la noción de autoridad.

Sin embargo, y a pesar del interés suscitado, esta discusión se tradujo, la mayoría de las veces, en una enconada crítica contra los excesos del autoritarismo

3 De éstos, 10 eran hombres y 10 mujeres. En términos de representatividad, se escogió a 5 estudiantes por cada uno de los niveles de la enseñanza media.

4 Esta discusión ha sido atizada igualmente por la crisis de los “metarrelatos" y el proceso de "desen- 
y, paralelamente, en un alegato permanente en torno a la crisis de la autoridad. La hegemonización de la discusión en torno a estos dos núcleos problemáticos eclipsó la reflexión sobre la definición misma de la noción de autoridad, las fuentes de su legitimidad y las formas de su adquisición. Al respecto sostiene Cueva:

"Por lo menos desde la segunda posguerra del siglo XX, buena parte del discurso político, de las movilizaciones contestatarias y hasta de las críticas a la vida cotidiana, se ha orientado contra el autoritarismo. De manera simultánea, distintos autores (...) han hecho notar que en el mundo moderno se ha perdido toda noción de lo que es la autoridad (...) detrás de esta contradicción priva una buena dosis de confusión" (Cueva, 2007: 244)

Se torna necesario, siguiendo este diagnóstico, superar la aparente paradoja presente en los discursos que oscilan entre la crítica al exceso y la crítica al déficit de autoridad, deslindando el contenido conceptual de esta noción y diferenciándola de otras categorías que comúnmente se le asocian (como la de poder, fuerza o dominación).

Uno de los trabajos pioneros al respecto fue el realizado por Max Weber. Desde su publicación a comienzos del siglo XX, la propuesta weberiana sobre la autoridad es probablemente la de mayor difusión a nivel académico. El autor parte diferenciando los conceptos de poder (Macht) y dominación (Herrschaft). La autoridad, en esta diferenciación, corresponde a la Herrschaft ${ }^{5}$ entendida como "la probabilidad de que, en un grupo determinado de personas, determinadas órdenes, o todas las órdenes, encuentren obediencia" (Weber, 2007: 59). La obediencia, como se colige, representa uno de los puntos medulares de la propuesta de Weber. Sin embargo, y esta es la principal diferencia con el Matcht, ella no se obtiene mediante la coacción o la fuerza sino por la creencia en su legitimidad. Es, por tanto, un tipo de obediencia

cantamiento" desatado en :-y por- la modernidad, eventos que resquebrajaron el sustrato trascendental que tuvo la autoridad durante la pre-modernidad (Fermandois, 1988).

5 Si bien la traducción literal es dominación, Weber utiliza este concepto para referirse a la autoridad. Esto no quiere decir que la autoridad sea idéntica a la dominación. Sin embargo, el autor, a pesar de distinguir en el texto ambas nociones, no aclara explícitamente la diferencia como sí lo hace entre el poder y la autoridad. 
voluntaria. Legitimidad y obediencia voluntaria son, en última instancia, el fundamento de toda autoridad.

Por otra parte, el autor señala que el tipo de legitimidad sobre el que descansa la obediencia voluntaria es precisamente el que permite diferenciar los distintos modos en que se ejerce la autoridad. Weber distingue tres tipos puros o ideales de autoridad de acuerdo a la fuente de legitimidad que éstas reclaman. La primera figura posee una legitimidad de índole racional, es decir, "se basa en la creencia en la legalidad del ordenamiento establecido y del derecho a dar órdenes por parte de quienes tengan la competencia (...) según ese ordenamiento" (Weber, 2007: 65). Dicha legitimidad racional permite la institución de una autoridad legal. Un segundo tipo de legitimidad es la proveniente de la tradición. La autoridad tradicional, por tanto, "se basa en la creencia usual en el carácter sagrado de tradiciones existentes desde siempre y en la legitimidad de los competentes para ejercer la autoridad en virtud de esas tradiciones" (Weber, 2007: 65). El último tipo reconocido por Weber corresponde a la autoridad carismática, es decir, aquella cuya legitimidad "se basa en la entrega extraordinaria a la santidad, heroísmo o ejemplaridad de una persona y del ordenamiento creado o revelado por esta persona" (Weber, 2007: 65). ${ }^{6}$

Tras la propuesta weberiana, la legitimidad y la obediencia se tornaron en nociones constitutivas de la autoridad. Así, desde la filosofía, Alexandre Kojève sostuvo que la autoridad es un tipo de relación social caracterizada por "la posibilidad que tiene un agente de actuar sobre los demás (o sobre otro), sin que esos otros reaccionen contra él, siendo totalmente capaces de hacerlo" (Kojéve, 2006: 36). En este caso la legitimidad opera inicialmente de manera inversa. Es decir, antes que producir obediencia, ésta inhibe las potenciales reacciones frente a la "decisión" u "orden" de la autoridad, presuponiendo que dicha reacción es una posibilidad efectiva. Por lo mismo, cuando la obediencia se funda en fenómenos que impiden la posibilidad de reacción, como el uso de la fuerza, la autoridad se diluye, dando paso a otro tipo de relación social (de

6 Tras describir los tipos de autoridad, el autor establece un pronóstico en torno a su evolución histórica. Así, al analizar los procesos de modernización de las sociedades occidentales, Weber auguró la progresiva expansión del tipo de autoridad legal-racional. Al respecto, una de las principales características de este tipo de autoridad es su impersonalidad, pues, la obediencia se otorga a alguien cuya posición en el ordenamiento legal lo faculta para dar órdenes (independiente de sus cualidades personales) bajo el supuesto de que es el ordenamiento mismo el que goza y le transmite su legitimidad. 
poder o de dominación). ${ }^{7}$ A su vez, dicha posibilidad implica que no existe una relación de autoridad sustancial, inalterable e imperecedera. Ésta siempre se encuentra "amenazada" y en riesgo de disolución. Por esto, concluye el autor, "en cada momento la posibilidad voluntariamente reprimida de la reacción puede actualizarse y así anular la Autoridad” (Kojève, 2006: 40).

Mientras para Weber la legitimidad funciona como catalizadora de la obediencia voluntaria y para Kojève como inhibidora de una reacción, desde el campo de la hermenéutica Gadamer sostiene que ésta emerge de un acto de reconocimiento. Así, la autoridad se instituye en el momento que "se reconoce que el otro está por encima de uno en juicio y perspectiva y que en consecuencia su juicio es preferente o tiene primacía respecto al propio" (Gadamer, 1977: 347). Con esta definición, Gadamer erige al conocimiento como el único fundamento legítimo de la autoridad, distanciándose de las propuestas anteriores, donde se apelaba a diversos tipos ideales y a diferentes legitimidades. Sin embargo, el autor mantiene el sustrato de la propuesta weberiana, pues, la autoridad sigue emergiendo de un acto de voluntariedad, que excluye constitutivamente la posibilidad de la fuerza o la coacción como mecanismo fundante de la obediencia.

Los autores hasta aquí tratados han preservado como elemento de análisis transversal una noción de autoridad cuya médula estaría constituida por la legitimidad. Ésta representaría el soporte instituyente de la obediencia voluntaria. Sin embargo, es necesario, para incluir a todo el espectro analítico que se ha ocupado de analizar el tópico de la autoridad, presentar las visiones que contrastan con los presupuestos hegemónicos anteriormente mencionados. En esta rivera se inscribe el registro de uno de los fundadores de la Escuela de Frankfurt y propulsor de la teoría crítica.

El tratamiento que Horkheimer realiza sobre la noción de autoridad parte de un diagnóstico histórico categórico: "la coacción, en su forma desnuda, no basta ya en modo alguno para explicar por qué las clases dominadas han soportado el yugo tanto tiempo" (Horkheimer, 2011: 163). Las relaciones de dominación, para el autor, no podrían explicarse exclusivamente como el resultado de la violencia "pura" ejercida por las clases dominantes. Por ello

7 Así como Weber postuló la existencia de tres tipos ideales de autoridad, Kojève distinguió cuatro figuras generativas: la del Padre, la del Amo, la del Jefe y la del Juez. 
Horkheimer pretende indagar en los aspectos culturales que permiten la interiorización de la dominación en los individuos y las sociedades.

Es, precisamente, en esta tarea de "inoculación" de formas coactivas que la noción de autoridad tendría un carácter central. En otras palabras, la autoridad sería una forma cultural mediante la cual se interiorizaría el principio de coacción. Su función final, en este algoritmo, sería la reproducción y perpetuación de las relaciones de dominación de clase. Sin embargo, y a pesar de su naturaleza instrumental, la valoración de la autoridad no sería unívoca, pues, si bien ésta representaría un soporte del aparato cultural para la interiorización de la dominación, también poseería la potencialidad de adquirir un carácter "progresista", es decir, promover el cambio social. Sería, pues, el contexto histórico específico y el impulso o la represión que la autoridad realiza sobre el despliegue de las fuerzas productivas el que determinaría el carácter opresivo o progresivo de la misma. ${ }^{8}$

Las distintas propuestas establecidas por los intelectuales en torno a la noción de autoridad nos proporcionan los insumos teóricos indispensables para el tratamiento de la autoridad pedagógica en específico. Al respecto, creemos indispensable fijar ciertos criterios que, dilucidados a partir de dichas propuestas, deben guiar conceptual y analíticamente el presente trabajo.

En primer lugar, y sintetizando a los autores revisados, entenderemos la autoridad como un tipo de relación social específica de mando-obediencia que se caracteriza por la voluntariedad con que se obtiene esta última, voluntariedad que se soporta en la creencia de una legitimidad particular y compartida.

La comprensión de la autoridad como un tipo determinado de relación social, a su vez, nos impele a reconocer que ésta contiene siempre una historicidad inherente, es decir, se ciñe a ciertas coordenadas espaciotemporales. La autoridad, en consecuencia, no emerge ni se reproduce de la misma manera en todas las sociedades y en todos los tiempos, sino que posee un carácter constitutivamente situado. Así, las formas que ésta adopta dependen de los modos específicos en que se establecen las relaciones sociales en una configuración colectiva determinada. Es por ello que, tal como

8 El ejemplo utilizado por el autor para explicar su propuesta es el de la burguesía. Durante los siglos XVI y XVII la subordinación de la burguesía a la monarquía era un factor productivo del desarrollo social (autoridad productiva), sin embargo dicha dependencia no se justificaba más en el siglo XIX, momento en que el desarrollo de las fuerzas productivas permitían a la burguesía materializar un cambio de la estructura política. En este contexto la sumisión monárquica fue una postura asumida por los segmentos más reaccionarios de la burguesía (autoridad inhibitoria). 
lo explicita Weber y Kojève, la autoridad se materializa en diversos tipos o figuras. Por otra parte, la historicidad de la autoridad supone, de acuerdo a lo sostenido por Horkheimer, que las condiciones contextuales y materiales influyen estructuralmente en su emergencia y despliegue. Las condiciones de producción de la autoridad, por tanto, deben ser consideradas en todo estudio empírico de la misma.

Finalmente, dicha historicidad determina que las fuentes de legitimidad de la autoridad, elemento tan preciado en la teoría weberiana, dependan de las características particulares de la sociedad en que ésta surge. La legitimidad, en consecuencia, no puede ser entendida como un aspecto apriorísticamente delimitado sino que es un soporte cuyo contenido específico se torna mutable.

\section{El debate sobre la autoridad pedagógica}

Como señalamos anteriormente, la autoridad no es un ente "esencial", petrificado e inmodificable sino, por el contrario, un tipo de relación social susceptible al cambio. Es por ello que, sin pretender establecer un recorrido exhaustivo, presentaremos dos tradiciones sociológicas que representan distintos "momentos" en el análisis y comprensión de la autoridad pedagógica moderna.

La primera de ellas es ilustrativa de las maneras con que se comprendió y estudió la autoridad pedagógica durante gran parte del siglo XX. La segunda, por su parte, constituye un intento por comprender las mutaciones que se han producido respecto de este molde "clásico" y las características de la autoridad pedagógica contemporánea.

La perspectiva de la sociología "tradicional"

Para comprender las características centrales de la autoridad pedagógica moderna hemos elegido a dos sociólogos que, por la trascendencia de su obra y 
la antinomia de sus tesis, nos permitirán dilucidar los elementos de continuidad y perseverancia histórica.

En "Educación como socialización", Durkheim sostiene que la autoridad pedagógica proviene del ascendiente moral del maestro sobre el estudiante. El profesor, en tanto mandatario del acervo de conocimientos de una sociedad determinada, se erige en su representante para las futuras generaciones. En este contexto, la única condición para la producción de la autoridad pedagógica es la voluntad y la convicción del maestro respecto de la enorme responsabilidad social y la "grandeza de la tarea" a la que debe responder. Es precisamente por dicha grandeza, por ser el mandatario de la gran persona moral de la sociedad, que Durkheim asimila la figura del profesor a la del sacerdote. Al respecto, señala el autor:

"Y lo mismo que el sacerdote es el intérprete de su Dios, el maestro es el intérprete de las grandes ideas morales de su tiempo y de su país. Por consiguiente, si se siente aferrado a esas ideas, si palpa toda la grandiosidad de las mismas, la autoridad que está contenida en ellas y de la que él tiene plena conciencia, entonces no podrá menos de ver cómo esa misma autoridad se comunica a su persona y a todo lo que de ella emana" (Durkheim, 1976: 112).

De este modo la producción de la autoridad pedagógica sería un acto de fe y convicción mediante el cual las ideas morales, en abstracto, son encarnadas por un representante particular. La autoridad, en consecuencia, es un acto de transferencia expedito del ascendiente moral de la sociedad hacia su representante.

Por otro lado, Bourdieu y Passeron sostienen que toda acción y comunicación pedagógica, en tanto imposición de un arbitrario cultural, autogenera una autoridad pedagógica. Ésta, por tanto, se presenta como un prerrequisito en la imposición de la "violencia simbólica". Señalan los autores:

"En tanto que poder de violencia simbólica que se ejerce en una relación de comunicación (...) la acción pedagógica implica

9 Este concepto alude a la "naturalización" arbitraria de la cultura producida por la clase dominante y su consiguiente inoculación en las clases subalternas a través de los procesos de escolarización. 
necesariamente como condición social para su ejercicio la autoridad pedagógica" (Bourdieu y Paseron, 1995: 51-52)

El carácter autogenerativo de la autoridad implicaría la indiferencia respecto de las condiciones de su producción. En el fondo, la autoridad pedagógica emerge automáticamente y se autoinstituye, preexistiendo a la facticidad de la relación pedagógica. Ella, por tanto, representa un prerrequisito de la relación profesor-estudiante y no su resultado. Los autores lo expresan de la siguiente manera: "En tanto que la acción pedagógica en vigor dispone automáticamente de una autoridad pedagógica, la relación de comunicación pedagógica debe sus características propias al hecho de que se encuentra totalmente eximida de producir las condiciones de su instauración y de su perpetuación" (Bourdieu y Paseron, 1995: 60). La autoridad pedagógica, por tanto, no requiere de ningún soporte para su emergencia, está dada de antemano por el sólo hecho de operar dentro de la institución educativa.

Como se puede apreciar, y a pesar de las enormes diferencias teóricas e ideológicas existentes entre la teoría de la socialización de Durkheim y la de la reproducción expuesta por Bourdieu y Passeron, ambas coinciden subyacentemente en su análisis respecto de la generación y producción de la autoridad pedagógica. En efecto, ya sea en la calidad de depositaria moral de la sociedad o como instrumento generado a priori para la imposición de la violencia simbólica, la autoridad escolar adquiere tal condición de manera externa a la relación pedagógica misma. En este contexto, el tema de la obediencia estudiantil, atributo inherente de la autoridad pedagógica, sería un problema vacuo, sino inexistente, en la medida que ella se encuentra legitimada externamente, generada automáticamente (mediando la convicción en el caso de Durkheim) y asegurada en su despliegue fáctico. Es por esto que ninguno de los autores se detuvo a profundizar en este problema. Siguiendo la lógica weberiana, por lo tanto, estos autores reconocerían una transmisión institucional de la legitimidad, situación que transforma directamente en autoridad a todo aquel que detente un determinado rango o cumpla una función de mando institucional.

En síntesis, y avizorando los elemento de continuidad que se presentan en ambas teorías, la autoridad pedagógica ha sido asumida por la sociología "tradicional" de la escolarización como un atributo de producción autopoyética, que se encuentra legitimado externamente, es decir, por fuera y anterior a la interacción profesor-estudiante, y que descansa sobre una obediencia asegurada 
de antemano, a consecuencia de lo que Durkheim denomina una cualidad análoga a la "sugestión hipnótica" manejada por la psicología.

Mutaciones en la autoridad pedagógica.

La perspectiva de la sociología contemporánea

Contraviniendo la noción de autoridad pedagógica manejada por las teorías sociológicas tradicionales, en las últimas décadas han surgido una serie de marcos interpretativos que comienzan a analizar la escuela a partir de la tesis del declive o desfondamiento institucional. Ella supone que si la institución ya no es capaz de funcionar con todo su potencial performativo sobre los sujetos, entonces las autoridades pierden el sustento que las legitimaba y, con ello, la capacidad de emergencia autopoyética que le asignaron las corrientes sociológicas "tradicionales".

En primer lugar, y para situarnos correctamente en las coordenadas de esta corriente interpretativa, es necesario precisar que la noción de "institución" alude a la capacidad de un determinado ordenamiento social para "instituir" o producir individuos acordes a las necesidades y particularidades que éste presenta. Al respecto señala Dubet: "utilizaremos la noción de institución en un sentido particular: el que tiene la función de instituir y de socializar. La institución es definida entonces por su capacidad de hacer advenir un orden simbólico y de formar un tipo de sujeto ligado a este orden, de instituirlo" (Dubet, 2007: 40-41). En este contexto, continúa el autor, la institución escolar se había caracterizado por crear un programa estructurador y una economía simbólica que permitían sacralizar su funcionamiento en tanto espacio configurador de la subjetividad moderna y constructor del lazo social. ${ }^{10}$ Para Dubet, el cambio de época ha significado la desestructuración de dicho programa y por tanto la pérdida del carácter instituyente que mantenía

10 Reconocemos, junto a Lewkowicz, la siguiente conceptualización de "lazo social": "Llamaré lazo social a la ficción eficaz de discurso que hace que un conjunto de individuos constituya una sociedad. Y a la vez, a la ficción social que instituye los individuos como miembros de esa sociedad. Porque no es la misma experiencia de sí mismo, de la sociedad, del mundo, si uno está instituido como polités ateniense, como laborator medieval, como burgués gentilhombre, como camarada soviético, como ciudadano, o como consumidor, o pariente en una red extendido de parentesco. El lazo, entonces, es la institución de una sociedad para los individuos, pero es también la institución del tipo de individuos pertinentes para esa sociedad" (Lewkowicz, 2008: 56). 
la escuela. Esta incapacidad instituyente, por tanto, sería la manifestación palmaria del declive institucional.

Por su parte, y en lo atingente a la problemática que revisamos, el declive de la institución habría generado una brecha insalvable entre el estatuto (lugar que el sistema asigna) y el oficio docente (maneras en que el profesor realiza efectivamente su trabajo). Así, el autor sostiene que el estatuto, pilar fundamental que durante la modernidad dotó automáticamente de legitimidad a la autoridad pedagógica, se ve eclipsado e impedido para realizar dicha transmisión en la actualidad. En este contexto, por tanto, el profesor debe obtener la obediencia a partir de su oficio, es decir, de las relaciones concretas que establece con los estudiantes. (Dubet, 2006: 171).

Otra propuesta enmarcada en esta "nueva sociología" de la educación es la de Duschatzky y Corea. Estas autoras sostienen, a partir del análisis sobre la realidad de las escuelas vulnerables de Argentina, que la institución educativa ha sufrido una alteración radical de su fundamento institucional y de su soporte estructural: el Estado-nación. De acuerdo a esta versión, la destitución del estado y su reemplazo por el mercado, producto de las políticas neoliberales impuestas en Latinoamérica en el último tercio del siglo XX, configuraron un escenario de declive de sus instituciones matrices. En este contexto, la escuela perdió su capacidad performativa sobre el imaginario colectivo y la hegemonía que ostentaba en la generación de una subjetividad específica, la del ciudadano, asociada al proyecto nacional. $\mathrm{Al}$ respecto concluyen las investigadoras: "el Estado-nación, mediante sus instituciones principales, la familia y la escuela, ha dejado de ser el dispositivo fundante de la 'moralidad' del sujeto" (Duschatzky y Corea, 2011: 26). Por ello, el declive de la institución escolar representaría el agotamiento del dispositivo pedagógico moderno, la consiguiente pérdida de la "autopoyesis" de la autoridad y la dispersión y heterogeneidad de fuentes utilizadas para la construcción de la subjetividad de las nuevas generaciones. ${ }^{11}$

Utilizando instrumentos teóricos similares, Lewkowicz y Corea sostienen la tesis del desfondamiento de las instituciones. De acuerdo a los autores, la escuela moderna dotaba de sentido a las personas y al colectivo nacional al inculcar ficciones discursivas estructurantes de la subjetividad.

11 El corolario de este diagnóstico es que la violencia escolar sería la principal expresión de la crisis institucional. Sobre esto señalan: "La violencia se presenta como un modo de relación que aparece en condiciones de impotencia instituyente de la escuela y de la familia, es decir en una época en que parecen haber perdido potencia enunciativa los discursos de autoridad y el saber de padres y maestros, que tuvieron la capacidad de interpelar, formar y educar en tiempos modernos" (Duschatzky y Corea, 2011:23). 
Fundamental al respecto era la ficción de la igualdad jurídica que instituía la figura del "semejante" o ciudadano. Sin embargo, una vez liberadas las fuerzas del mercado, la escuela perdió su capacidad instituyente. De esta manera, la institución escolar sufriría la dilución de su contenido o fondo y sólo permanecería como una forma o "caparazón" institucional (Lewkowicz y Corea, 2011).12

Finalmente, y de acuerdo a Martuccelli, el fundamento de la autoridad pedagógica actual, en el contexto del declive o desfondamiento de las instituciones, reposa en la capacidad relacional del docente. Ésta, en consecuencia, antes que por la tradición, el rol o el conocimiento, es construida cotidiana y pragmáticamente dependiendo de las características individuales del profesor y de los recursos de que dispone para "seducir" a los estudiantes, legitimando su posición de mando y asegurando, siempre de manera provisoria y contingente, la obediencia voluntaria de los mismos (Martuccelli, 2009).

Siguiendo a esta nueva propuesta sociológica, el declive, destitución y/o desfondamiento institucional modificaría radicalmente las condiciones de producción de la autoridad pedagógica. Ésta, que emergía autopoyéticamente durante la modernidad, ahora debe fundamentarse a partir de la capacidad práctica de los actores escolares para construir un nuevo "suelo compartido". La emergencia de la autoridad pedagógica, por tanto, se daría contingentemente y se soportaría en las capacidades relacionales del maestro. En este contexto, adquiere relevancia la figura compuesta por los denominados "maestros errantes". Por su parte, la nueva forma de configuración de la autoridad pedagógica constituiría la base de una "pedagogía a la intemperie", es decir, que se encuentra desprovista de un techo institucional que la cobije y legitime (Duschatzky, 2012). De allísu fragilidad y el proceso permanente de construcción en el que debe soportarse. Es, precisamente, la radical transformación en las condiciones de producción de la autoridad pedagógica, desde aquella asegurada externamente hacia una caracterizada por la fragilidad y la autogeneración constante, la que generaría la sensación de crisis y decadencia tan pregonada en el último tiempo.

Ahora bien, asumiendo que existen dos escuelas sociológicas que postulan distintas directrices en torno a las formas de producción de las

12 Lewkowikcz profundiza en este proceso desde una perspectiva general de las instituciones y no sólo referido a la escuela (Lewkowikcz, 2008). 
relaciones de autoridad en la escuela, se torna indispensable revisar cómo han sido estudiadas éstas en el contexto nacional.

\section{Estudios empiricos sobre las relaciones de autoridad en la escuela chilena}

En su gran mayoría, los estudios respecto de las formas de ejercicio de la autoridad pedagógica en Chile adhieren tácitamente a la tesis de la sociología "moderna", insertando su emergencia dentro de un marco crítico en torno al proceso democratizador. En efecto, los estudios empíricos sobre la autoridad pedagógica en el escenario nacional tributan a la teoría de la transmisión directa e institucional de la legitimidad, añadiendo, para el caso particular, una fuerte crítica a los remanentes autoritarios con que se tiñen las prácticas de mando-obediencia escolar. ${ }^{13}$

$\mathrm{Al}$ respecto, Leticia Arancibia ha estudiado el imaginario de los actores escolares y las relaciones de poder en el Chile postdictatorial concluyendo que la imposición de un "imaginario autoritario" se ha perpetuado en las praxis concretas al interior de la institución educativa. Ello, a pesar de la intención de las políticas públicas y de los esfuerzos estudiantiles por democratizar el espacio escolar. (Leticia Arancibia, 2008: 385) Por su parte Llaña ha estudiado sistemáticamente las interpretaciones y significaciones de los estudiantes en torno a la realidad escolar y las relaciones con el profesorado. Sus investigaciones constatan que los alumnos mantienen una discursividad que interpreta dichas relaciones como extremadamente jerárquicas y persistentemente abusivas. De este modo, los jóvenes significarían la realidad escolar como una instancia coercitiva y de control, y a los profesores como instrumentos de dominación que desconocen las culturas o "habitus" estudiantil-juveniles. Por ello sostiene la profesora:

"los estudiantes de estas nuevas generaciones visualizan la escuela como un espacio de poder, de directivos y profesores, y desde su propia mirada, como una institución poco democrática. Normas que afectan más bien a los estilos que los unen como grupos etareos, prohibidas en el

13 Debemos explicitar que somos nosotros los que hacemos la adscripción entre dichos estudios y la concepción "tradicional" de la autoridad pedagógica y no los propios autores. Al mismo tiempo, es necesario resaltar que en la mayoría de los trabajos citados no se establece una diferenciación en torno a la noción de autoridad, asimilando este concepto al de dominación y poder. 
espacio escolar y sancionadas rigurosamente, son rechazadas y resistidas con una variabilidad de estrategias que tensionan la convivencia" (Llaña, 2010: 61).

Finalmente, Marambio y Guzmán han analizado cómo la mantención de las prácticas autoritarias en las escuelas nacionales se vería reforzada por una arquitectura erigida y experienciada como un espacio carcelario orientado a maximizar las posibilidades de control disciplinario y de obediencia estudiantil compulsiva. Por esto concluyen: "la representación social que los jóvenes entrevistados construyeron de su espacio escolar es la de un sistema obligatorio, marcado por la verticalidad y la vigilancia, en donde las estructuras físicas reflejan y están al servicio de los fines normativos establecidos por la autoridad" (Marambio y Guzmán, 2009: 82).

En síntesis, los principales estudios sobre las relaciones de autoridad pedagógica en Chile demuestran la persistencia de un modelo basado en la imposición jerárquica y autoritaria, es decir, en la utilización de un poder autoinstituido y discrecional frente al cual los estudiantes se presentan a merced, razón por la cual su obediencia es "arrancada" coactivamente. La pretendida imagen de la democratización de las relaciones sociales, de acuerdo a este marco, se desdibujaría en prácticas concretas y generalizadas de preservación del autoritarismo en la escuela, situación que generaría una dinámica relacional caracterizada por la permanente conflictividad. Esta conclusión, a su vez, podría llevarnos a inferir que, en Chile, la autoridad escolar no ha sufrido ninguna crisis -tópico de moda en el sentido común-, por lo menos en su potencia de mando. Ello, consecuentemente, supondría que sus condiciones de producción han permanecido inalterables. En este sentido, las investigaciones empíricas reseñadas tributarían subyacentemente a la teoría sociológica "tradicional" sobre la autoridad pedagógica, aquella propuesta por Durkheim y Bourdieu.

Sin embargo, estos estudios no agotan el espectro total de las investigaciones orientadas a desentrañar las modalidades con que opera la relación de autoridad en el escenario educativo nacional. En este sentido, y aunque no adhiera explícitamente a la tesis del declive institucional, los trabajos de Zamora y Zerón dan cuenta de una realidad distinta a la proporcionada por las investigaciones recién expuestas. En efecto, estos autores han indagado en las formas que estudiantes y docentes perciben y construyen las relaciones de autoridad, particularmente en establecimientos educativos de la capital que reciben a sectores empobrecidos. Respecto de los estudiantes, la investigación 
demostró que ellos reconocen 5 formas de ejercicio de la autoridad (Zamora y Zerón, 2010). Ellas son:

- "Autoridad pedagógica como la aplicación justa e implacable de la norma escolar"

- "Autoridad pedagógica como oportunidad para el aprendizaje"

- "Autoridad pedagógica como el poder discrecional"

- "Autoridad pedagógica como un vínculo afectivo"

- "Autoridad pedagógica como exigencias morales"

Ahora bien, antes que describir cada una de estas modalidades, lo que nos interesa es recalcar el hecho de que, para fundar una asimetría relacional avalada por estudiantes y profesores, se recurre a diversas fuentes de legitimidad, todas ellas provenientes de las dinámicas concretas que se establecen entre ambos. Por lo tanto, la legitimidad de la autoridad pedagógica ya no se soportaría exclusivamente en el abrigo institucional y el estatus docente. Esta situación se torna aún más evidente en el caso de los estudios centrados en las narrativas docentes. Al respecto, la conclusión a la que arriban los investigadores es que "actualmente la autoridad pedagógica no es una condición provista automáticamente por la escuela y tampoco por la formación universitaria. Ello es consistente cuando se considera a la autoridad como un fenómeno social situado y no un concepto a priori (en este contexto). La autoridad se construye en la interacción social cotidiana con los alumnos (...) En otros términos, el actor decisivo para construir la autoridad son los alumnos; ellos se convierten para los profesores en el principal y quizás único referente" (Zamora y Zerón, 2009: 179).

En síntesis, los estudios de Zamora y Zerón demuestran que las relaciones de autoridad en el escenario educativo actual dependen de la capacidad interactiva (oficio) del docente y de las legitimidades que emergen en el espacio y las interacciones cotidianas donde se encuentran estudiantes y profesores. Ello a su vez, y aunque no sea reconocido por los autores, nos posibilita concluir que la tesis del declive institucional puede rastrearse en la realidad escolar nacional.

Existiendo, pues, estudios empíricos que respaldan las dos corrientes sociológicas revisadas, debemos adentrarnos directamente en el relato de los 
estudiantes para, desde allí, verificar cómo se están construyendo las relaciones de autoridad en la escuela chilena actual.

\section{La voz de los estudiantes en torno a las relaciones de autoridad en la escuela}

De acuerdo a los análisis que tienden a encumbrar al "conflicto" como una de las principales expresiones relacionales que se produce entre los distintos estamentos que interactúan en el campo educativo, las interpretaciones que los estudiantes sostendrían respecto de los profesores y de las autoridades institucionales serían unánime y categóricamente negativas. Es así como los jóvenes chilenos representarían y tipificarían a los docentes como "autoritarios, burócratas, desconfiados, sin vocación y desmotivados” (Llaña, 1999).

El escenario escolar y las relaciones humanas, en este contexto, se caracterizarían por una opacidad asfixiante cuya dinámica central estaría dada por la búsqueda de un poder que niega la legítima diversidad del "otro". En este sentido, el estudiante se presentaría como un sujeto constantemente amenazado en su particularidad socio-cultural debido a la pretensión homogeneizadora de la "máquina" escolar. En el otro extremo, y en concordancia con esta autorrepresentación estudiantil, las autoridades serían los responsables de erradicar las expresiones de heterogeneidad y de imponer autoritariamente el mandato institucional.

Este sombrío panorama sobre las relaciones de autoridad en la escuela no es, precisamente, el que dibujaron nuestros entrevistados. En efecto, antes que una sentencia categórica, un juicio taxativo o una visión unívoca respecto de las autoridades escolares, particularmente de los profesores, nuestros actores revelaron una realidad integrada por múltiples matices. La tesis del "todo o nada" ("todos los profesores son...", "todas las autoridades son...") no fue esgrimida por ningún estudiante y, en su lugar, surgieron las apreciaciones clasificatorias. El discurso estudiantil, por tanto, genera un imaginario capaz de distinguir, de diferenciar, de establecer criterios demarcatorios que inhiben la tentación de generalizar en una trama única la experiencia en torno a las relaciones de autoridad en la escuela.

En este sentido, la primera unidad de clasificación tiene un carácter binómico y su criterio de demarcación es el par estricto/“buena onda” o pesado/ 
simpático. El establecimiento de esta diferenciación básica desmiente por sí mismo la pretendida uniformidad o valoración categóricamente negativa que se le ha achacado al estudiantado. De esta manera lo explica Fernando $\left(4^{\circ}\right) .^{14}$

"habían profes buena onda que hacían las clases entretenidas igual y, bueno, uno los respetaba porque ellos se hacían respetar igual. Pero había algunos profes que no, que les gusta tratar mal a los alumnos. No sé si tratar mal, sino que ser estricto, y con esos profes uno no tiene mucha relación"

Añade Camila $\left(4^{\circ}\right)$ : “Los profesores, algunos diferentes, no sé po, simpáticos, agradables, te enseñaban bien, y otros por tanto, no tan simpáticos, medios pesados los viejos". La demarcación binómica es explicitada reiteradamente en la gran mayoría de los relatos recabados y representa el soporte mediante el cual los estudiantes calibran, en una primera instancia, las relaciones con los adultos que ejercen un puesto de autoridad en la institución escolar.

Sin embargo, y a pesar de que esta operación no se realiza de manera tan transversal como la división binómica, varios estudiantes dan un paso más en los criterios demarcatorios. Algunos, refiriéndose específicamente a la autoridad, llegan a postular la existencia de varios "grados" o "niveles" representados por distintos grupos de profesores. $\mathrm{Al}$ respecto, señala Beatriz $\left(4^{\circ}\right)$ :

"hay profesores que tienen como más una amistad con los alumnos, que llegado el día... ellos también tienen ese nivel de autoridad, ellos les dicen algo y los alumnos los van a acatar porque ellos se llevan bien. En cuanto a lo otro, que también como que tienen su grado pero después se llevan, ya no pasó, entonces ya no le importa. Como casi si "yo ya estudié", "yo ya hice lo que tenía que hacer, ustedes salen perdiendo al final". Y después están los otros más autoritarios que son como más con las amenazas. Y siempre los alumnos terminan en inspectoría, terminan expulsados. Son entre los distintos tipos de profesores"

Más adelante la misma alumna agrega:

"hay algunos (profesores) que son mayormente autoritarios. Son, por cosas pequeñas, ya empiezan a tomar decisiones muy alteradas. $\mathrm{Y}$

14 El número entre paréntesis representa el nivel de enseñanza media en que se encuentra el estudiante al momento de ser entrevistado. 
los otros son, su nivel de autoridad es justo y necesario. Yo creo que hay otros que no tienen ningún nivel de autoridad"

Como se puede colegir de las narraciones anteriores, para los estudiantes no existe una experiencia única de la autoridad escolar, mucho menos, por tanto, una experiencia exclusivamente negativa. Antes que eso, la autoridad escolar es enjuiciada a partir de criterios demarcatorios que permiten agrupar, en un primer momento, a las autoridades "buena onda", valoradas positivamente, de aquellas estrictas o "pesadas" en quienes recae una sentencia crítica.

Sobre este criterio básico y transversal, puede operar una nueva clasificación que adquiere mayor complejidad, pues, se realiza a partir del aquilatamiento del "tonelaje" o "grado" de autoridad. Bajo esta perspectiva existirían tres tipos de autoridades, a saber, aquellas que presentan un grado excesivo ("autoritarias"), aquellas cuyo grado es el óptimo o justo (lo que vendría a corresponder a una "autoridad en sí") y aquellas caracterizadas por poseer un grado inferior al mínimo indispensable ("no tienen autoridad").15

De esta manera, en las narrativas escolares las relaciones de autoridad son caracterizadas de manera múltiple y heterogénea. El juicio estudiantil, en consecuencia, es un juicio matizado, que no "despecha" ni "acoge" en un mismo acto, y de manera contundente, a todo tipo de autoridad institucional, sino que produce categorías de valoración que operan como el tamiz mediante el cual se conceptúa a cada una de éstas de manera individual.

Esta primera conclusión, que desdeña la interpretación de la autoridad como una "máquina" de imposiciones y que sostiene la existencia de autoridades reconocidas como positivas por los estudiantes, supone la entrada al juego de un nuevo tópico, el de la legitimidad. En efecto, la perspectiva a la que nos arribó el discurso estudiantil abre un espectro de análisis escasamente visitado por la interpretación impositiva de la autoridad. Lógicamente, ésta podía esquivar la problemática en la medida que toda autoridad impuesta quedaría, en principio, eximida de generar las condiciones de su legitimidad. Sin embargo,

15 Incluso algunos estudiantes, nuevamente desmintiendo los juicios categóricos, señalan que un mismo profesor puede, dependiendo del momento, representar las dos formas constituyentes de la clasificación binómica, es decir, ser "buenas onda" y al mismo tiempo estrictos. Los matices de la autoridad, en consecuencia, se podrían encarnar en una misma persona. Al respecto señala Ricardo $\left(3^{\circ}\right)$ : "Los profes, bueno, ta el pesao, ta el simpático, ta también el, cómo se dice, el... hay uno que son como más en confianza, que te retan. Pero las características del principal, nada po, que les gusta, por ejemplo, hay tiempos que les gusta lesiar y hay un tiempo que les gusta hacer clase. Y ahí hay que respetarlos". 
y a riesgo de parecer majaderos, reiteramos que nuestros testimonios revelan que no todas las autoridades son impuestas y que no toda obediencia proviene de la coacción. Si asumimos esta premisa, por lo tanto, se torna imperioso inquirir en las razones de la obediencia o, si se prefiere, en el contenido de la legitimidad.

\section{Legitimidad y razones de la obediencia}

La legitimidad, como revisamos en la propuesta weberiana sobre la autoridad, es un aspecto medular en tanto representa el soporte primario sobre el que se asienta la obediencia voluntaria. Es precisamente ella la que permite delimitar el espacio correspondiente a la autoridad de aquel que ocupa la "dominación" y el "poder".

De acuerdo al relato de los estudiantes entrevistados, la obediencia hacia los profesores emana fundamentalmente de tres fuentes: ${ }^{16}$ el acercamiento empático-afectivo, la actividad académico-pedagógica y el poder discrecional en la gestión de la convivencia y la interacción pedagógica. Éstas, a su vez, no son raíces o manifestaciones "puras" en la construcción de la legitimidad docente. Por el contrario, las modalidades para la obtención de una obediencia voluntaria tienden a mixturarse y yuxtaponerse, configurando relaciones múltiples y heterogéneas donde prevalece o se acentúa alguno de aquellos criterios o rasgos. De esta manera, cuando hablamos de tres fuentes de la legitimidad docente nos referimos, fundamentalmente, a la predominancia de una de ellas antes que a su presencia exclusiva. Dicha predominancia, al mismo tiempo, puede mutar dependiendo del contexto y los momentos en que es ejercida y o demandada. En efecto, para los estudiantes no existe una adscripción única, incuestionable y a perpetuidad de un agente escolar con alguna de las fuentes de la legitimidad. En este sentido, y es fundamental explicitarlo para evitar generar una imagen inmovilista y petrificada de la legitimidad y de las relaciones de autoridad, un mismo agente escolar puede fundar su legitimidad

16 Recordemos que Zamora y Zerón (2010) identifican cinco grandes razones de la obediencia estudiantil. Sin intentar desmentir sus resultados, de hecho nuestros criterios se corresponden con la propuesta de éstos, sostenemos que las tres categorías engloban algunas de las legitimidades reseñadas por los autores y que en nuestras entrevistas aparecen sólo de manera tangencial o minoritaria. 
en un criterio para determinadas situaciones y modificarlo cuando el momento o el contexto varía. ${ }^{17}$

De esta manera, la legitimidad no posee un contenido único ni está nucleada a partir de un sedimento apriorísticamente definido, esencial e inmutable. Antes bien, para su configuración se puede apelar a una serie de elementos cuyo acceso o posesión puede provenir de diversas modalidades y transitando variados caminos.

\section{Acercamiento empático-afectivo}

Este es, sin lugar a dudas, el principal expediente mediante el cual los profesores erigen su autoridad frente a los estudiantes. En efecto, ellos constantemente, al momento de evocar las características de un buen profesor y las razones por las cuales se le obedece, recurren a la imagen de la cercanía afectiva y la capacidad empática. Ricardo $\left(3^{\circ}\right)$ nos comenta que el mejor profesor es el "que te escucha, te comprende y te ayuda harto. Te enseña, te escucha y los problemas que tenís, y mientras eso, te va enseñando”. Del mismo modo, Carlos $\left(2^{\circ}\right)$ señala que el buen docente es aquel que "es comprensivo, amigable, le gusta compartir, cuando tiene que ser pesado lo es, pero es un buen profesor".

La afectividad y la cercanía empática, desdeñada por la escuela moderna y su pretensión exclusivamente académica, se alza como la principal herramienta generadora de vínculos entre alumnos y profesores. Es por ello que los estudiantes exaltan y reconocen a los profesores que demuestran una genuina compenetración con las diversas problemáticas que les afectan. Al respecto, Carlos $\left(2^{\circ}\right)$ responde de la siguiente manera cuando se le pregunta cómo los profesores obtienen la obediencia de sus estudiantes:

"Yo creo que siendo así como buena onda, hablando con los alumnos, cosas así, como enseñándoles. Porque hay algunos que llegan, son como los jóvenes, llegan, pasan materia, y llegan nomás. En cambio

17 Un ejemplo de aquello son los profesores jefes que utilizan la modalidad del involucramiento personal cuando ejercen su jefatura y recurren a otra fuente de legitimidad cuando se enfrentan al mismo curso pero en su calidad de profesor de asignatura. 
los que se dedican a conversar, tiran la talla con los alumnos, esos son los que se ganan el respeto"

De acuerdo al imaginario estudiantil, en consecuencia, no basta con el simple cumplimiento formal de la labor docente para ser reconocido como una autoridad pedagógica. La dictación de la clase, por tanto, antigua forma legitimada que dotaba al profesor de un status que transmitía de manera instantánea la autoridad requerida para ejercer el oficio, no es ya la instancia fundamental para generar relaciones de obediencia voluntaria. En las condiciones actuales, los alumnos exigen que el profesor se involucre personal y emotivamente con ellos, los acompañe en sus inquietudes y solidarice con sus problemas, estableciendo un genuino "vínculo afectivo" (Zamora y Zerón, 2010: 11).

Por su parte, el acercamiento empático puede provenir y manifestarse de diversas maneras y en distintos niveles. La forma más básica de ejercer esta modalidad es mediante la generación de un clima de confianza. Para ello es indispensable que el profesor sepa escuchar y simpatizar con el grupo de estudiantes. El procedimiento primario que permite configurar dicho clima es la concesión de tiempos para la conversación informal y la generación de espacios para "tirar la talla". Al respecto sentencia Camila $\left(4^{\circ}\right)$ que los buenos profesores son los que "siempre te han apoyado, siempre han estado contigo, también, tiran la talla. Si no todo es serio en la sala de clases, si tiene que haber emociones, reírse".

La risa, por tanto, demuestra el establecimiento de un espacio mínimo de confianza y de distensión que funciona como plataforma de vinculación entre estudiantes y profesores. Sin embargo, sobre ella puede asentarse una relación más fuerte cuyo desarrollo permite aumentar el "grado" de la autoridad. Ello dependerá del nivel de involucramiento personal del docente con el desarrollo integral de sus alumnos. En efecto, aquellos profesores que presentan una mayor preocupación y que realizan acciones concretas que demuestran su compromiso con los estudiantes adquieren una mayor validez relacional. Estos profesores son, en palabras de los estudiantes, los que "se la juegan". Es ilustrativa la imagen que nos presenta Yerco $\left(2^{\circ}\right)$ al momento de explicarnos por qué obedecía a determinado profesor:

"Porque cuando, digamos, yo iba mal en su ramo, él me decía, pucha, me tiraba arriba, me decía "tú soy inteligente, te la podís" me decía, "haz las tareas, si yo te las puedo recibir", "estudia" me decía 
cuando estaba ahí. Me veía afuera, me salía a buscarme, cuando no me veía en la sala me salía a buscarme, me llevaba a la sala y me pasaba las tareas po. Encuentro que era un buen acto de él po, porque él no nos retaba, nos decía, siempre me decía que estudiara po, que yo no era tonto, que podía po"

La legitimidad basada en el acercamiento empático-afectivo, por tanto, supone un alto grado de involucramiento y preocupación del profesor por la trayectoria de sus estudiantes, así como un reconocimiento de éstos hacia la autoridad escolar, reconocimiento que aumenta a medida que es más profundo el compromiso personal del docente.

La apertura de la escuela hacia las emociones, la risa y la cercanía afectiva, cercenada desde una perspectiva academicista de la escolarización, es uno de los principales desafíos para la construcción de la autoridad pedagógica contemporánea, más aún cuando los estudiantes la demandan cada vez con mayor ímpetu. Dicha exigencia, de hecho, progresivamente se instala como un prerrequisito para el establecimiento de cualquier relación dentro del escenario educativo. Edgar $\left(4^{\circ}\right)$ lo demuestra al concluir, respecto de la relación con sus profesores, que "eso es lo que me gusta, me gusta la cercanía. No me gusta ver como un robot parado".

Ahora bien, para comprender adecuadamente la forma en que opera este tipo de legitimidad es necesario anotar dos observaciones. La primera de ellas concierne a las causas por las cuales los estudiantes están dispuestos a obedecer a este tipo de profesores y, la segunda, se refiere a las manifestaciones prácticas $o$, si se prefiere, al tipo de obediencia obtenida mediante este expediente.

Respecto de lo primero, sostenemos que la jerarquía o la asimetría relacional, prerrequisito de toda relación de autoridad, es aceptada por los estudiantes en tanto conciben que ella emana de una genuina preocupación del docente por su crecimiento. En este sentido, el estudiante comprende la relación con el profesor como una especie de complicidad cuyo objetivo es lograr su "verdadero" desarrollo. Convencido de esto, el joven reconoce en el adulto su mayor experiencia, académica y vital, y le confiere una preeminencia a sus puntos de vista. Es necesario explicitar que para el estudiante se trata precisamente de ello, un punto de vista mejor posicionado y no una verdad 
incuestionable. Es por ello que los mandatos específicos del profesor son asumidos como un consejo antes que como una orden.

La obediencia, por tanto, proviene del reconocimiento (Gadamer, 1977) y se vivencia como una "retribución" por el compromiso y la preocupación demostrada o como la respuesta de reciprocidad ante la relación de complicidad mutua. En otras palabras, los estudiantes obedecen voluntariamente pues perciben que el profesor actúa motivado exclusivamente por buenas intenciones y busca permanentemente el bienestar de sus alumnos. Si efectivamente se materializa este acto de reconocimiento, los estudiantes conceden una preeminencia a la opinión del docente, quien, debido a la amplitud de su experiencia, puede decidir con mayor propiedad los caminos adecuados para arribar a dicha meta.

Sin embargo, el mentado reconocimiento no es un acto o un proceso simple, como podría parecer si reducimos la cuestión a un par de discursos de "buena crianza" por parte del profesor. Lejos de ello, para el imaginario estudiantil este tipo de legitimidad exige dos requisitos al docente: la sinceridad en el compromiso y la coherencia con los actos. En efecto, las denuncias de dobles discursos, de caretas humanitarias y de inconsecuencias fácticas son innumerables. De acuerdo a los estudiantes, y en palabras de Camila $\left(4^{\circ}\right)$, no son pocos los profesores que "contigo muestran una cara y después como que con sus colegas te tiran como pa abajo". Las declaraciones, por tanto, no bastan para acceder completamente a este tipo de legitimidad, ellas deben estar acompañadas por intenciones genuinas y actos concretos. Los profesores, para "ganarse" o aumentar su grado de autoridad, deben demostrar que "se la juegan”.

Respecto de la segunda cuestión, el tipo de obediencia concedido, los estudiantes mantienen una estricta coherencia con las premisas de la exigencia relacional que estipulan. De este modo, si ellos pretenden que el profesor se involucre subjetivamente en las problemáticas que deben afrontar, entonces la obediencia tendrá un carácter eminentemente personal. En el fondo, se obedece a una persona específica no por su status o adscripción a un estamento que oficialmente tiene la facultad de mando, sino por las cualidades personales que impregnan el ejercicio de dicha posición. En otras palabras, si la obediencia se vivencia como retribución o reciprocidad es por la relación intersubjetiva creada y no por una normatividad externa, sea esta explícita o consuetudinariamente 
formulada. Es una persona singular la depositaria de la confianza, la que le permite tomar decisiones posteriormente acatadas.

Esta particularidad del tipo de acercamiento empático-afectivo lleva aparejada una consecuencia fundamental para los modos en que se manifiesta la obediencia voluntaria. Ésta tiende a expresarse de manera indiferenciada en términos espacio-temporales, es decir, se traslada a todos los ámbitos en que se despliega la relación misma, razón por la cual el profesor adquiere un mando que sobrepasa los límites del horario y la sala de clases. La autoridad, en este caso, se transforma en un elemento inmanente de la persona que la ostenta. Sin embargo, y este es el "riesgo" fundamental de dicho tipo de obediencia, cuando la confianza del estudiante en el docente se ve mermada (generalmente por constatar las incoherencias antes reseñadas) este último pierde instantánea y definitivamente la autoridad conferida y, en vistas a lo que los estudiantes viven como una traición, pasa a formar parte de la pléyade de profesores "malos". Si la autoridad personalizada exige una entrega sincera y completa, la pérdida de la misma supone una profunda desafección que igualmente se expresa sin diferenciar momentos ni espacios. Tal profesor, en consecuencia, difícilmente podrá reconquistar su autoridad, ni siquiera en el momento de su clase.

Actividad académico-pedagógica

Aunque no tan preponderante como la modalidad expuesta recientemente, una segunda fuente de legitimidad esgrimida por los estudiantes es aquella que proviene directamente de las acciones del profesor en la sala de clases. En este caso, es a partir de la interacción pedagógica misma desde donde se extraen los fundamentos de la autoridad docente, originando lo que Zamora y Zerón (2010) denominan una "autoridad pedagógica como oportunidad para el aprendizaje” (Zamora y Zerón, 2010).

La legitimidad obtenida mediante la actividad académico-pedagógica se manifiesta, por tanto, a través de la capacidad que demuestra el profesor para cautivar a los estudiantes con sus clases y generar una adecuada disposición para el aprendizaje de su audiencia. La autoridad, bajo esta modalidad, se verifica primariamente en aquel docente que es capaz de "hacer una clase entretenida". 
Ilustrativo al respecto es el comentario de Yango $\left(1^{\circ}\right)$ para quien la obediencia se concede a aquel que "sabe explicar bien la esta (la materia), y sabe cómo hacer una clase entretenida pa que no se aburran”. Respecto de lo mismo, Patricio $\left(3^{\circ}\right)$ señala que las buenas relaciones se mantienen con aquellos profesores "que te ayudan, siempre están al lado de uno, así, te explican bien. Siempre andan detrás de uno."18 En este caso, como vemos, antes que el compromiso afectivo entre dos sujetos lo que se evidencia es un compromiso o un respeto estudiantil por el rol estatuido oficialmente y, fundamentalmente, por la materialización efectiva de los objetivos pedagógicos.

En esto no hay que confundirse. Anteriormente señalamos que ya no bastaba con dictar la clase para asegurar una obediencia voluntaria, lo que podría resultar paradójico con la idea del compromiso o respeto al rol. Sin embargo, existe una diferencia sustancial entre ambas proposiciones. Mientras la primera se basa exclusivamente en el polo de la "enseñanza", la segunda se soporta en el eje del "aprendizaje". Bajo estos parámetros, el profesor no adquiere autoridad por la mera realización formal de una clase sino por la capacidad de que aquella enseñanza se afinque como conocimiento significativo en los estudiantes. La legitimidad, por tanto, la ostenta el profesional que es capaz de realizar dicho trayecto, de consumar su función profesional. En el fondo, la obediencia se delega a aquel docente que transmite efectivamente un determinado conocimiento atendiendo a las diversas y específicas modalidades de aprendizaje de sus estudiantes.

Por lo mismo, en esta vertiente de la legitimidad el asunto prioritario para los estudiantes es la capacidad didáctica del profesor, la flexibilidad en las formas de la enseñanza para atender a un público heterogéneo y culturalmente diverso y la tenacidad de sus intentos por darse a entender frente al estudiantado. Sobre esto señala Denisse $\left(1^{\circ}\right)$ :

"La forma de enseñar me gusta... porque hay algunos que, hay algunos alumnos que les cuesta más aprender las cosas y otros que aprenden al tiro. Entonces, este profesor, enseña una y otra y otra vez la misma materia hasta que a todos les queda"

Si la raíz de la legitimidad en esta modalidad difiere de aquella presentada en el apartado anterior, entonces las formas específicas que soportan y

18 Recordemos también la opinión anteriormente citada de Fernando (4º): "Eso varía, depende del profesor, depende la actitud del profesor igual, porque habían profes buena onda que hacían las clases entretenidas igual y, bueno, uno los respetaba porque ellos se hacían respetar igual". 
vehiculizan el tipo de obediencia también presenta modificaciones. En primer lugar, los estudiantes que esgrimen la capacidad académico-pedagógica del profesor para erigir su autoridad suelen participar, en parte, de un imaginario tradicional de la institución educativa. Para ellos, el objetivo principal de la escuela es transmitir efectivamente un determinado conocimiento, en consecuencia, el profesor es una autoridad en tanto tiene la capacidad para llevar a cabo dicho cometido.

Bajo esta perspectiva, la obediencia voluntaria generalmente emerge de una predisposición a acatar las órdenes del profesor, pues, reconocen que ellas permitirán el acceso a tal saber. En el fondo el profesor representa, por sus estrategias didácticas y su esfuerzo pedagógico, precisamente dicho acceso. Es la "llave maestra", el que conoce las particularidades de los estudiantes y sabe cómo seducirlos o convencerlos para generar algún interés por el aprendizaje de su disciplina.

Subordinada a esta primera razón de la obediencia, se encuentra la valoración hacia el profesor por su "vocación". Esta representa, en el imaginario estudiantil, el carácter inclaudicable del compromiso docente, en un contexto desmejorado, con el aprendizaje de sus estudiantes. El discurso juvenil reconoce a los profesores que no cejan en sus principios pedagógicos y que se esfuerzan para que sus enseñanzas sean asumidas por todos sus alumnos sin exclusiones, a pesar de las dificultades que encuentra en su camino. Es así como, en este segundo ramal, la obediencia se orienta al reconocimiento de lo que para los estudiantes constituye la "verdadera esencia" del ejercicio docente.

Así, mientras la primera razón de la obediencia opera fundamentalmente en una perspectiva individual mediante la cual el estudiante reconoce que dicho profesor "le" permite el acceso a un determinado conocimiento, la segunda funciona dentro del espectro comunitario de la clase, es decir, el alumno abstrae las consecuencias individuales del actuar docente e inscribe al mismo bajo la orientación normativa del beneficio colectivo y la consumación de la "vocación". La imbricación de ambas modalidades, en consecuencia, genera una autoridad legitimada a partir de criterios configurados para valorar la calidad de la interacción académica-pedagógica.

Por otra parte, la principal característica de la obediencia voluntaria obtenida mediante este expediente es que presenta una mayor diferenciación espacio-temporal que aquella proporcionada por la modalidad del acercamiento empático-afectivo. El profesor se mueve dentro de un marco de autoridad que 
presenta un grado superior de delineamiento. De esta manera, y en la medida que es el conocimiento académico su principal soporte, la "fuerza" de la autoridad será mayor precisamente en los momentos y espacios en que se lleva a cabo dicha transmisión, diluyéndose progresivamente una vez terminada la misma. En breve, la obediencia se presta mayormente en la sala y durante el horario de la clase específica y tiende a no trasladarse a otros espacios y momentos. Por esta misma razón la pérdida de legitimidad no tiene un carácter irreversible o "profundo", tal y como se manifiesta en la modalidad anterior. Todo depende de la capacidad docente para reinventarse, para reacomodar sus estrategias didácticas y reencausar la motivación estudiantil. Cuando el objetivo, la función social y pedagógica del profesor logra nuevamente materializarse, la legitimidad reemerge sin vivenciar los trastornos emotivos que supone su pérdida en el caso precedente.

Poder discrecional en la gestión de la convivencia y la interacción pedagógica

De acuerdo a las interpretaciones de los alumnos, una última instancia para lograr la obediencia voluntaria es la utilización facultativa de las normas por parte de los docentes. El imaginario estudiantil reconoce que éste es un recurso disuasivo que permite al profesor direccionar ciertas conductas estudiantiles.

Ahora bien, es necesario explicitar que no nos referimos directamente al uso discrecional de la sanción, sino al grado de estrictez con que se resguardan las obligaciones, explícitas y tácitas, estipuladas para cada estamento institucional. En este sentido, la regulación y gestión de la convivencia y la interacción pedagógica entre estudiantes y profesores se mantiene dentro del marco oficial y reglamentario sin que el profesor exceda las prerrogativas formales estatuidas.

Sin embargo, el poder discrecional apunta a que en ocasiones dichas estipulaciones son distorsionadas o su sentido es trastocado por los propios profesores para lograr la obediencia de sus estudiantes. Por lo tanto, si bien la norma es estrictamente aplicada y no puede cuestionarse la "legalidad" de sus decisiones, la obediencia es "arrancada" mediante procedimientos que los estudiantes consideran una exageración o extralimitación de las facultades docentes. $\mathrm{Al}$ respecto, Ricardo $\left(3^{\circ}\right)$ señala que los profesores adquieren su 
autoridad "haciéndose respetar, así, retando, no dando oportunidades a los alumnos. Así por ejemplo, te mandaste una, ya, cortaste, chao".

En este caso, el profesor no sanciona, no amenaza, no utiliza recursos explícitamente diseñados para forzar o corregir la voluntad del estudiante, simplemente deja de dar oportunidades, lo que, si bien no puede ser cuestionado desde una perspectiva "legal" o reglamentaria, si supone una distorsión de lo que los estudiantes perciben debería ser la actitud de un buen profesor.

Contrariando esta imagen estudiantil, los profesores que utilizan su poder discrecional en la gestión de la convivencia y de la interacción pedagógica tienden a ser categorizados como profesores "cuadrados" o "autoritarios" y se caracterizarían por la pretensión de totalizar el control sobre los estudiantes. $\mathrm{Al}$ referirse a uno de dichos docentes Beatriz $\left(4^{\circ}\right)$ señala:

"la profesora se llevaba más por el nivel autoritario. "No, ustedes se callan, porque ustedes se callan", "ustedes se sientan porque yo quiero que se sienten", "tú no vay, porque no quiero que vayai", "yo no quiero que hagai esto", entonces estaba como tan... y siempre era como que pensaba que andábamos armando conspiraciones, así, contra ella"

En este registro, por tanto, el profesor es representado como un agente con un poder discrecional sobredimensionado y cuyas acciones y consecuencias podrían afectar directamente alguna de las dimensiones de la trayectoria escolar del estudiante. Éste último, en consecuencia, obedecería como un modo de evitar o aminorar los riesgos que supondría dicho accionar. Al respecto la sentencia de Carlos (3) es elocuente: "Yo creo que (los estudiantes) obedecen por el medio a que les digan algo, o por el medio a que los reten"19.

El miedo o, mejor dicho, la conciencia sobre las potenciales consecuencias negativas derivadas de las decisiones docentes serían el soporte principal y la razón de la obediencia en esta modalidad. Sin embargo, y es necesario reiterarlo, no es un miedo a la sanción explícita sino a las consecuencias informales que podrían derivar del desacato, aquellas no estatuidas en los reglamentos escolares pero que inciden significativamente en la trayectoria escolar del

19 En otra circunstancia, al comparar la autoridad de los profesores con la de los auxiliares y el equipo paradocente, el mismo estudiante señala: "a los profesores como que hay un respeto diferente, porque a ellos como que le tienen no miedo, sino que saben que el profesor los puede anotar, saben que el profesor les puede citar al apoderado, les puede poner una mala nota, cualquier cosa". Por su parte Yesenia $\left(2^{\circ}\right)$ mantiene una opinión similar: "la mayoría no está ni ahí. En el colegio quizás es donde tienen un poco más de respeto, pero por miedo a que les puedan citar al apoderado". 
estudiante. Explicitamos esta diferencia, pues, cuando la obediencia se funda directamente en el miedo a la sanción, generalmente los estudiantes perciben que lo que existe no es una autoridad sino un poder descarnado.

Finalmente, la demarcación espacio-temporal de este tipo de autoridad es difusa, parcial y móvil, pues, mientras los profesores pretenden que opere de manera indefinida, al modo de la obediencia por acercamiento empáticoafectivo, los estudiantes presionan por delimitarla al ámbito exclusivo de la clase. De allí que este tipo relacional sea el más conflictivo de los tres.

\section{"Ganarse el respeto" v/s "hacerse respetar". Los diversos caminos hacia la autoridad}

"Razones de la obediencia”, "disciplina" o "legitimidad" (y otras como "dominación" y "resistencia") son conceptos que no fluyen espontáneamente en los relatos de los jóvenes entrevistados. Antes que nociones integradas a sus vocabularios cotidianos -situación que no implica su desconocimiento o incomprensión-son abstracciones teóricas, construcciones analíticas mediante las cuales se pretende extraer y configurar, desde las narrativas primigenias, un sustrato categorial.

Por el contrario, si tuviéramos que elegir una noción propia y "natural" de la narrativa estudiantil, definitivamente el concepto de "respeto" (Sennett, 2003) es el que se utiliza de manera más generalizada y al que mayormente recurren para englobar el problema de las relaciones de autoridad en el escenario escolar.

El respeto, por tanto, es el contenido mediante el cual los estudiantes representan el elemento central que da consistencia a la autoridad y el lente a través del cual se verifica o niega su existencia. La construcción de la autoridad docente, bajo este prisma, representa el juego o la situación en que un agente es respetado o, en contraposición, al que se le falta el respeto. La hegemonía de la alusión al "respeto" como soporte de la autoridad no supone, sin embargo, una concepción homogénea del mismo, ni estipula una fórmula monolítica para su 
adquisición. Pareciera que los estudiantes distinguen y juzgan valóricamente distintos tipos y grados de "respeto".

Sobre esto, y por el carácter explícito con que fueron enunciadas, distinguimos dos entradas principales o dos lógicas relacionales que vehiculizan este "sentimiento" o actitud hacia los docentes. Ellas pueden ser sintetizadas en las fórmulas de "ganarse el respeto" y "hacerse respetar". Para comprender cada una, recordemos los siguientes extractos de dos relatos expuestos anteriormente y que versan sobre las formas en que los docentes logran la obediencia de sus estudiantes.

Carlos $\left(2^{\circ}\right)$ : "los que se dedican a conversar, tiran la talla con los alumnos, esos son los que se ganan el respeto"20

Ricardo (3): "haciéndose respetar, así, retando, no dando oportunidades a los alumnos"21

"Ganarse el respeto" y "hacerse respetar" son los dos caminos y las dos formas relacionales que, para el imaginario estudiantil, cimentan la legitimidad de las autoridades escolares. Ambas fórmulas difieren en dos aspectos medulares: la temporalidad que reclaman y la preeminencia del actor específico dentro de la relación de autoridad, asumida ésta como un tipo de interacción entre un agente y un paciente (Kojève, 2006).

De esta manera, mientras el "ganarse el respeto" opera en el plano temporal del proceso, el "hacerse respetar" lo hace en el del acontecimiento. Del mismo modo, la primera de estas fórmulas está volcada o concede preeminencia al polo de los estudiantes (paciente), mientras la última se orienta hegemónicamente hacia el ejecutor o la figura de autoridad (agente).

20 Sobre lo mismo Fernando $\left(4^{\circ}\right)$ señala "Y otros profes no po, otros profesores, la mayoría era así (impositivos), pero algunos profesores eran, se ganaban el respeto con cariño y con afecto".

21 A su vez Yesenia (2०) señala que los profesores adquieren su autoridad "haciéndose respetar, cuando el alumno, cuando él dice, un ejemplo tan básico, "sí", el alumno dice "no", el va "sí, sí, sí". Y si no cumplís la regla te vas a inspectoría, que es lo más típico que hacen, no pueden hacer nada más, porque obviamente no pueden pegarle a un alumno. De levantarles la voz, la levantan. Pero lo más grave que pueden hacer es llamar al inspector y echarte". 
Finalmente, y como consecuencia de dichas diferencias, las formas de ejercicio de la obediencia difieren entre ambas fórmulas.

Para comprender mejor la especificidad de cada una de estas tramas de construcción de la legitimidad docente se torna necesario desarrollar las diferencias enunciadas.

"Ganarse el respeto" se ubica temporalmente en las coordenadas del proceso, pues, supone una condición inicial indistinta, donde la autoridad no opera de manera preexistente, y, por tanto, requiere de un decurso que debe ser transcurrido para su obtención. El respeto, en consecuencia, no está en el principio de la relación pedagógica, no se presenta como prerrequisito de la autoridad sino como algo a lo que se aspira, instalado más allá de lo que inicialmente se dispone (que sería simple y formalmente poder). El profesor, por tanto, debe "ganar" algo, adquirir aquello de lo que no dispone para ser considerado una autoridad. La fundación de una asimetría legítima es un recorrido permanente, un proceso, mediante el cual el docente logra la adhesión estudiantil, es decir, gana aquello de lo que carece en un comienzo, inviste su poder con la legitimidad que le conceden los estudiantes, trasformando su ubicación formal de preeminencia estamentaria en una posición que deviene en autoridad.

Es por ello, a su vez, que esta fórmula supone la preeminencia relacional de los estudiantes. En esta perspectiva de la legitimidad obtenida a través de un proceso, la misión del profesor es "ganarse el respeto" de sus alumnos, por tanto, son ellos los que concederán finalmente las credenciales de su autoridad. En otras palabras, son los propios alumnos, en última instancia, los que deciden ceder o negar su obediencia voluntaria y, en consecuencia, permiten o inhiben la transformación del poder en autoridad. En la práctica esta lógica supone que el profesor no sólo debe velar por cumplir su función reglamentaria y formal, la enseñanza, sino que debe conocer aquellos elementos que le permitirán ser valorado por los estudiantes, pues sobre estos deberá fundar su legitimidad y construir la respectiva relación de obediencia voluntaria. En la lógica del imaginario estudiantil, "ganarse el respeto" es la fórmula para ganar autoridad sin que nadie pierda.

Por su parte, "hacerse respetar" opera en el plano del acontecimiento, es decir, la autoridad se funda, o aspira a fundarse, en el momento mismo, y cada una de las veces, en que se establece la relación pedagógica cotidiana. La obediencia, en este registro, emergería de manera casi instantánea en todas 
aquellas situaciones en que el profesor utiliza alguna de sus prerrogativas. En este sentido, la autoridad, contrariando la lógica anterior, no se obtiene en un transcurso "hacia", sino en una acción específica que opera siempre en el tiempo presente. De hecho, ésta se vivencia, en la experiencia de los alumnos, como una serie discontinua de situaciones en que el profesor toma una decisión facultativa mediante la cual espera un acto específico de obediencia estudiantil.El "hacerse respetar" se materializa, por tanto, a través de una concatenación de decisiones no interconectadas que buscan el "hecho" inmediato de la obediencia. Ésta, a su vez, se transforma en un modo de reacción ante las decisiones del profesor y no en el soporte de una relación duradera con el mismo.

Por lo mismo, dicha modalidad está centrada en el "ejecutor" o detentador de la autoridad y no en los estudiantes. En este caso, el carácter reactivo de la obediencia estudiantil supone que el profesor es el principal responsable para su despliegue y materialización. Ello, pues, la obediencia debería emanar como respuesta mecánica ante las decisiones facultativas derivadas del posicionamiento jerárquico-estamentario. Coherentemente, el inicio de toda autoridad es la acción docente misma, ésta funda la obediencia. La consecuencia lógica de esta configuración es que el docente adquiere preeminencia por sobre el estudiante, actor que queda relegado a una posición donde responde secundaria y pasivamente a una acción previa. De esta manera, y desde una perspectiva de la orientación o preeminencia relacional, el "hacerse respetar" opera bajo una direccionalidad signada por la imposición sobre los "otros" y no por la delegación desde los "otros", tal y como ocurre en la fórmula precedente.

Ahora bien, cada una de estas lógicas es valorada de distinta manera por los estudiantes. Mientras el "ganarse el respeto" adquiere un cariz positivo y fundaría una autoridad relativamente permanente, pues, es construida en el largo plazo del proceso y con la aquiescencia de sus "destinatario", el "hacerse respetar" es considerada como una estrategia negativa que sólo logra imponer una autoridad transitoria, que perdura exclusivamente en los instantes inmediatamente posteriores al hecho que la constituye, situación que generalmente incide en la generación de un clima relacional polarizado que, en el largo plazo, afrenta la propia legitimidad docente. En el fondo, mientras el "ganarse el respeto" construye una actitud de obediencia que opera como base permanente para la relación entre estudiantes y autoridades, el "hacerse 
respetar" genera un hecho de obediencia que es constitutivamente transitorio y, por tanto, impedido de configurar una plataforma relacional duradera.

Ahora bien, lastres fuentes parala adquisición de la legitimidad desarrolladas anteriormente pueden ser adscritasa algunadeestas dosgrandeslógicasconstitutivas de la autoridad. En efecto, de acuerdo al relato y la valoración de los estudiantes, tanto el acercamiento empático-afectivo como la óptima actividad académicopedagógica son modalidades que permiten a los profesor "ganarse el respeto" de sus estudiantes, mientras la utilización del poder discrecional en la gestión de la convivencia y la interacción pedagógica se inscribe como un procedimiento que funciona para "hacerse respetar". De las observaciones realizadas previamente se colige que las primera dos razones de la obediencia son valoradas positivamente por los estudiantes mientras la última suele generar un rechazo o, cuando menos, una posición crítica de los mismos.

\section{Conclusión}

A comienzos del siglo XX el sociólogo Max Weber, uno de los principales precursores en el estudio sobre las relaciones de autoridad, auguraba la progresiva expansión de la denominada "autoridad legal". Ella se encontraba respaldada por una legitimidad de índole racional basada en la creencia respecto de la legalidad del orden establecido. En el fondo, era la propia confianza en el sistema la que dotaba de legitimidad a aquellos que detentaban un puesto de mando (Weber, 2007: 65).

La sociología de la educación, en concomitancia con esta propuesta, pensó las relaciones de autoridad en el escenario escolar bajo el mismo alero de la confianza y la transmisión institucional. En este contexto, la legitimidad del profesor y la aceptación estudiantil de la asimetría relacional fueron aspectos instalados y vivenciados como presupuestos apriorísticos del ordenamiento educativo. Por ello, la producción de toda relación de autoridad tenía un carácter autopoyético, donde la obediencia voluntaria se encontraba resguardada y era concebida como una actitud obtenida con anterioridad a la interacción pedagógica misma.

Sin embargo, los cambios estructurales vividos desde fines de la centuria pasada, ha tornado obsoleta esta matriz de producción de la autoridad pedagógica.El estatus es incapaz de infundir legitimidad, la escuela no genera institucionalmente 
un lazo social asimétrico reconocido por todos los sujetos sociales, la autoridad ha sido desinvestida. ¿Significa esto el fin de la autoridad?. No.

La tesis de la caída "en picada" de la autoridad pedagógica no es, precisamente, la que deja entrever el relato de los estudiantes entrevistados. Por el contrario, éstos reconocen a la autoridad en tanto ella se funda sobre una legitimidad compartida. Dicha legitimidad, a su vez, se soporta en distintos ámbitos y acude a diversas instancias para su constitución. No podríamos, por tanto, sentenciar categóricamente que existe una situación de crisis uniforme y global de la autoridad en el escenario escolar.

Lo antedicho no significa que la autoridad pedagógica haya permanecido inalterable y no se hayan verificado modificaciones en su status, en sus condiciones de emergencia y en las configuraciones específicas mediante las cuales se manifiesta. En el fondo, la tan pregonada "crisis de la autoridad" representa la decadencia de un modo específico de producción y legitimación que predominó en los tiempos de expansión del sistema de escolarización. Mas, dicha crisis que afecta a un modo específico de construcción de la autoridad no significa la disolución de la autoridad misma en tanto categoría analítica y relación social.

En la práctica, existe un desplazamiento significativo de las raíces primarias que conceden legitimidad a la autoridad escolar. En efecto, si durante la modernidad o, para ser más exactos, durante gran parte del siglo XX ésta se cimentó bajo la premisa de que la posición institucional, el rol o la función sistémica, imprimían inmediatamente en el profesor una autoridad, hoy la mera posición o status formal no asegura la obediencia voluntaria de los estudiantes. Éstos, de acuerdo a nuestros relatos, privilegian actualmente otra fuente de legitimidad, aquella centrada en la acción misma del docente y sus atributos personales antes que en sus credenciales. La obediencia voluntaria, por tanto, cambia o desplaza el "insumo" que la constituye, desplazamiento que va desde la institución y su capacidad inherente para imbuir de autoridad a los agentes educativos hacia estos mismos y su desenvolvimiento cotidiano en las interacciones con los estudiantes.

En el reconocimiento de estas nuevas legitimidades se encuentra la posibilidad de refundar las relaciones de autoridad sobre un lazo social y educativo compartido por todos los actores escolares. 
Referencias bibliográficas

Araujo, Kathya y Martuccelli, Danilo (2012). Desafíos Comunes. Retrato de la sociedad chilena y sus individuos, Tomo I y II, LOM, Santiago.

Arancibia, Leticia (2008). Relaciones de poder y desigualdad en la escuela secundaria. El caso de Chile de transición y los desafios desde el punto de vista de la democratización. (Tesis para optar al grado de Doctor en Sociología). Universidad Católica de Louvain, Bélgica.

Bourdieu, Pierre y Passeron, Jean-Claude (1995). La reproducción. Elementos para una teoría del sistema de enseñanza, Laia, Barcelona.

Cueva, Marcos (2007). "De la gran liberación al fin de la autoridad”, Revista Mexicana de Sociología, Vol. 69, No 2, México, pp. 243-275.

Dubet, Françoise (2005). “'Mutaciones institucionales y/o neoliberalismo?”, Revista Colombiana de Sociología, No 25, pp. 63-80.

Dubet, Françoise (2006). El declive de la institución. Profesiones, sujetos e individuos en la modernidad, Gedisa, Barcelona.

Durkheim, Émile (1976). Educación como socialización, Sígueme, Salamanca.

Duschatzky, Silvia y Corea, Cristina (2011). Chicos en banda. Los caminos de la subjetividad en el declive de las instituciones, Paidós, Buenos Aires.

Duschatzky, Silvia (2012). Maestros errantes. Experimentaciones sociales en la intemperie, Paidós, Buenos Aires.

Fermandois, Joaquín (1988). "Totalitarismo y autoritarismo como nuevos sistemas políticos", J. Barceló, (ed.) Ideologías y totalitarismos, Editorial Universitaria, Santiago.

Gadamer, Hans-Georg (1977). Verdad y Método. Fundamentos de una hermenéutica filosófica, Sígueme, Salamanca. 
Hobsbawm, Eric (1998). Historia del Siglo XX, Crítica, Buenos Aires.

Horkheimer, Max (2011). Autoridad y familia y otros escritos, Paidós, Barcelona.

Kojève, Alexandre (2006). La noción de autoridad, Nueva Visión, Buenos Aires.

Lewkowicz, Ignacio y Corea, Cristina (2011). Pedagogía del Aburrido. Escuelas destituidas, familias perplejas, Paidós, Buenos Aires.

Lewkowicz, Ignacio (2008). Pensar sin Estado. La subjetividad en la era de la fluidez, Paidós, Buenos Aires.

Llaña, Mónica y Escudero, Ethel (1999-2000). "Establecimientos educacionales en conflicto: Grupos de resistencia en su interior", Revista Enfoques Educacionales, Volumen 2 (2), pp. 155-166.

Llaña, Mónica (2010). “Convivencia escolar: disímiles construcciones simbólicas en oposición”, Revista Enfoques Educacionales, Volumen 11 (1), pp. 55-64.

Llaña, Mónica (2011). La convivencia en los espacios escolares. Una incursión hacia su invisibilidad, Departamento de Educación FACSO, Santiago.

Marambio, Javier y Guzmán, Sofía (2009). “La construcción de la escuela como espacio carcelario: una representación social de los jóvenes relativa a la (sobre) vivencia (en) de su espacio escolar", Redondo (Ed.), Juventudy enseñanza media en Chile del Bicentenario, Antecedentes de la revolución pingüina, OPECH, Santiago.

Martuccelli, Danilo (2009). "La autoridad en la sala de clases. Problemas estructurales y márgenes de acción”, Diversia, No1, Valparaíso, pp. 99-128.

Mucchielli, Alex (1996). Diccionario de métodos cualitativos en Ciencias Humanas y Sociales, Síntesis, Madrid.

Weber, Max (2007). Sociología del poder. Los tipos de dominación, Alianza, Madrid.

Zamora, Guillermo y Zerón, Ana María (2008). “Autoridad pedagógica. Un análisis desde la perspectiva de los estudiantes de la enseñanza media”, Boletín 
de Investigación Educacional, Volumen 23, No 2, Santiago, pp. 103-122.

Zamora, Guillermo y Zerón, Ana María (2009). “Sentido de la autoridad pedagógica actual. Una mirada desde las experiencias docentes”, Estudios Pedagógicos, Volumen XXXV, Nº1, Valdivia, pp. 171-180.

Zamora, Guillermo y Zerón, Ana María (2010). "Caracterización y sentido actual de la autoridad pedagógica en escuelas chilenas de sectores de pobreza", Revista Española de Pedagogía, Vol. 68, No 245, pp. 99-116 